\title{
Hormone replacement therapy is associated with improved verbal declarative memory in healthy relatively recent postmenopausal
} women

\author{
Evangelia Papavasiliou* and Sandra Sunram-Lea
}

Address: Lancaster University, Greece

* Corresponding author

\author{
from International Society on Brain and Behaviour: 2nd International Congress on Brain and Behaviour \\ Thessaloniki, Greece. 17-20 November 2005 \\ Published: 28 February 2006 \\ Annals of General Psychiatry 2006, 5(Suppl I):SI 22 doi:I0.II86/I744-859X-5-SI-SI 22
}

\begin{abstract}
Background
The efficacy of Hormone Replacement Therapy (HRT) for cognitive health in postmenopausal women has been systematically questioned during the last decade. Although epidemiological and clinical research have suggested that HRT may exert protective effects on the prophylaxis of neurodegenerative diseases and beneficial effects on cognitive function, the Women's Health Initiative Memory Study (WHIMS) contradicted these claims. The purpose of this study was to reassess the effects of HRT on cognitive function in an attempt to account for two potential confounding factors that might have generated the negative clinical findings reported by the WHIMS i.e. subjects' age and educational level.
\end{abstract}

\section{Materials and methods}

Forty healthy postmenopausal women (private clinic patients; last natural menstrual period $<3$ years), matched for age and education, freely consented to enter the study and were allocated in two groups according to their participation in HRT (i.e. HRT group $(\mathrm{n}=20)$ with an average duration of treatment $>1$ year without interruption since menopause and non-HRT group $(\mathrm{n}=20)$. Neuropsychological testing included tests of verbal declarative memory (California Verbal Learning Test), attention and concentration (Digit Vigilance Test) and problem solving ability (Matchstick problem). General functions and comparability of the groups were assessed by a family, past-medical and gynaecological history.

\section{Results}

No statistically significant differences between the groups were observed for the digit vigilance test (attention and concentration) and the matchstick problem (problem solving ability). However, the scores obtained through the immediate and delayed components of the memory tests revealed a statistically significant better performance in the group of women treated with HRT where fewer errors were recorded.

\section{Discussion}

The existing evidence supports that HRT use is associated with improved verbal declarative memory in healthy relatively recent postmenopausal women. Conversely, no effect of HRT has been observed on attention, concentration and problem solving ability. Finally, the negative results published by the WHIMS could be possibly attributed to subjects' age and educational level that might have acted as confounding factors for maintaining cognitive performance.

\section{References}

I. LeBlanc ES, Janowsky J, Chan BK, et al.: Hormone replacement therapy and cognition: systematic review and meta analysis. JAMA 200I, 285: I 489-I499.

2. Rymer J, Wilson R, Ballard K: Making decisions about hormone replacement therapy. BMJ 2003, 326:322-326.

3. Rapp SR, Espeland MA, Shumaker SA, et al.: Effect of estrogen plus progestin on global cognitive function in postmenopausal women: the Women's Health Initiative Memory Study: a randomized controlled trial. JAMA 2003, 289:2663-2672.

4. Shumacker SA, Legault C, Rapp SR, et al:: Estrogen plus progestin and the incidence of dementia and mild cognitive impairment in postmenopausal women. JAMA 2003, 289:265I-2662. 